\title{
A new method for demonstration of central effects of analgesic agents in man
}

\author{
HE TOREBJÖRK, W SCHADY, JL OCHOA* \\ From the Department of Clinical Neurophysiology, University Hospital, Uppsala, Sweden, and the Division \\ of Neurology, ${ }^{*}$ University of Wisconsin, Madison, Wisconsin USA.
}

SUMMARY A new method of eliciting experimental pain in man is described. Microelectrodes are inserted percutaneously into the peripheral nerves of awake subjects, and are positioned close to nociceptive fibres in order to elicit pain during intraneural electrical stimulation. Under fixed stimulation conditions the estimated magnitude of evoked pain remains relatively stable, unless a high stimulus frequency is used, which may lead to excitation failure of nociceptive fibres. This method can be employed to test for possible central modulation of pain, for instance by analgesic agents, since peripheral receptors are bypassed.

The use of experimental pain in man in combination with psychophysics has made it possible to obtain quantitative data about the efficacy of analgesic agents. Most methods involve the application of radiant heat, algesic chemicals or electric currents to the skin, mucosae or accessible skeletal structures. Such tests, however, provide little information about the agent's site of action, since they activate peripheral nociceptors and hence the whole nociceptive sensory system. In order to distinguish peripheral from central effects, it is necessary to employ a noxious stimulus which bypasses nociceptors but nevertheless selectively activates nociceptive units.

These conditions are fulfilled by the technique of intraneural electrical stimulation. Following the introduction of microneurography by Vallbo and Hagbarth, ${ }^{1}$ it became possible to record afferent discharges directly from within the nerves of human subjects by means of tungsten microelectrodes. A further development was the use of the same intraneural electrodes to stimulate electrically mechanoreceptive or nociceptive units. ${ }^{2}$ When the latter are activated intraneurally, subjects report pain projected to a discrete area of skin (or deep structures if the electrode tip is situated within a muscle nerve fascicle) supplied by the impaled

Address for reprint requests: Dr HE Torebjörk, Dept of Clinical Neurophysiology University Hospital, S-751 85 Uppsala, Sweden.

Received 31 October 1983 and in revised form 21 February 1984. Accepted 23 February 1984 nerve. Such pain can be reproduced at will and is amenable to psychophysical magnitude estimation. If under these conditions an analgesic drug is administered or some other putatively painrelieving procedure is applied, any observed fluctuations in the estimated magnitude of pain cannot be due to depression of peripheral receptor sensitivity-regardless of whether this occurs or not-but rather to modification of central processing of nociceptive inputs. This technique therefore represents a new method of evoking experimental pain in man and provides a means of testing central effects of analgesic agents. In this report we describe the method and discuss factors which may affect its reproducibility.

\section{Methods}

\section{Electrode insertion}

Tungsten microelectrodes were inserted in the peripheral nerves of nine healthy subjects aged $22-44$ years at either the median nerve in the upper arm, $10-15 \mathrm{~cm}$ above the elbow, the ulnar nerve at the wrist, the common peroneal nerve as it winds round the fibular head, or the superficial peroneal nerve in the lower leg. Electrodes were about 5 $\mu \mathrm{m}$ wide at the tip and were coated with resin lacquer except for an exposed area at the tip less than $150 \mu \mathrm{m}$ long. They were inserted percutaneously into the nerve in accordance with standard microneurographic technique..$^{3}$ Once inside the nerve, the electrode could be used either to record multi-unit or single nerve fibre signals, or to activate fibres electrically by means of intraneural microstimulation. ${ }^{2}$ Square wave electrical pulses of $0.25 \mathrm{~ms}$ duration were delivered through the active electrode from a Grass 
S48 constant voltage stimulator. This elicited muscle twitching and/or pain when a muscle nerve fascicle was impaled, and cutaneous sensations of various qualities when a skin nerve fascicle was impaled. ${ }^{4}$ By moving the electrode in small steps it was usually possible to place the tip in such a position that pain was evoked at low stimulus amplitudes, projected to either skin, muscle, joint or bone. A stimulation site was considered adequate if (a) pain was the first evoked sensation at a threshold no higher than $1 \mathrm{~V}$, and (b) quality and threshold were consistent in repeated trials. At such sites $C$ nociceptive or sympathetic activity could usually be discriminated when switching to recording mode. ${ }^{\circ}$ Single unmyelinated fibre recordings were, however, not considered indispensable if pain was adequately evoked on intraneural stimulation.

\section{Determination of appropriate stimulus parameters}

Once the electrode had been suitably positioned, trains of stimuli were delivered at a stimulus amplitude sufficient to induce moderate to severe pain but with only a minimum of concomitant distracting sensations such as tapping or buzzing in the skin, or muscle twitching. The stimulus amplitude was then kept constant. Various train durations and stimulus frequencies were tried in the course of three preliminary experiments in which pain was projected respectively to the skin, to muscle, and to bone. Throughout individual stimulus trains subjects were asked to rate continuously the magnitude of evoked pain by moving a lever along a $13 \mathrm{~cm}$ long visual analogue scale. Zero on this scale denoted absence of pain, even if other sensations were felt, and the top end corresponded to maximum tolerable pain. The lever was attached to a linear potentiometer connected to a storage oscilloscope out of sight of the subjects. Displayed rating curves were photographed or stored on magnetic tape for subsequent analysis.

One further preliminary experiment involved the use of two intraneural electrodes placed in the superficial peroneal nerve $4.5 \mathrm{~cm}$ apart, one to be used for stimulating, the other for recording purposes. Small adjustments were made in their position until they were both lying in the same fascicle, judging by the fact that the receptive fields of multi-unit responses recorded with them coincided, as did the projections of sensations evoked when stimulating intraneurally with either electrode. Electrical pulses were then delivered through the distal electrode while the proximal electrode was used for recording. In this way it was possible to monitor directly the responses of nociceptive fibres at different stimulus frequencies, and to correlate nociceptor activation with the magnitude of evoked pain.

\section{Determination of variability in pain ratings over time} In ten experiments the electrode was positioned in the same way as above and the stimulus amplitude was equally kept constant. Stimulus trains of $3 \mathrm{~s}$ duration at $10 \mathrm{~Hz}$ were repeatedly delivered at intervals of 5 or $10 \mathrm{~min}$. On each occasion, the subject was asked to estimate the magnitude of evoked pain at its peak in numerical terms. The first stimulus train was presented as standard and assigned a value (usually 100 ). All subsequent magnitude estimations were done relative to this standard on an open-ended ratio scale. When a figure other than $\mathbf{1 0 0}$ was used as standard, values were later normalised and changes in pain ratings were expressed as a percentage of the initial standard value. In between trains, the stimulating electrode was occasionally used for recording in order to make sure there was no change in recordable afferent or efferent fibre activity. If there was, this was taken to indicate electrode shift and the experiment was terminated.

\section{Test experiment using zomepirac}

The method was tested in a single experiment using the same procedure following oral administration of zomepirac sodium, a prostaglandin synthetase inhibitor with powerful analgesic properties. After establishing that recording conditions were stable and pain ratings remained unchanged for $30 \mathrm{~min}$, a single oral dose of $100 \mathrm{mg}$ was given. The effect on pain ratings was then studied for $150 \mathrm{~min}$.

\section{Results}

\section{QUALITY AND PROJECTION OF PAIN}

Pain evoked by intraneural stimulation was described by most subjects as dull, aching or boring. Despite its vague aching character, it was fairly focally projected to a discrete circular or oval area of skin, muscle, joint or bone. The mean size of this area was $150 \mathrm{~mm}^{2}$ when projected to the skin and $500 \mathrm{~mm}^{2}$ when projected to deep structures, corresponding to diameters of 1.4 and $2.5 \mathrm{~cm}$, respectively. Evoked pain was "pure" in five out of 11 experiments at the stimulus amplitudes required to produce at least moderately severe pain. Mean stimulus amplitudes used were $0.9 \mathrm{~V}$ when stimulating in the median nerve and $1.0 \mathrm{~V}$ when stimulating in the common peroneal nerve. At such amplitudes, pain was accompanied by a slight intermittent tap-

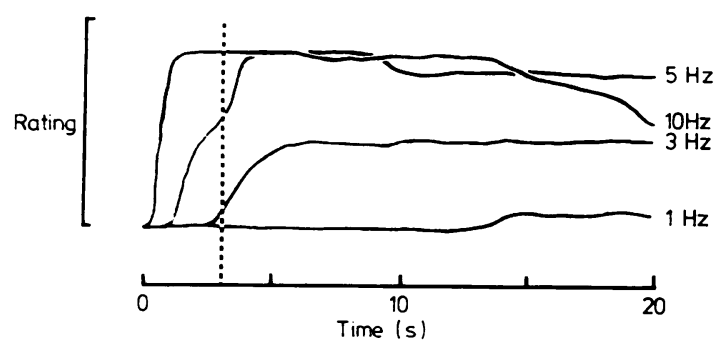

Fig 1 Voltage analogue of a subject's continuous pain rating during intraneural stimulation at $2.3 \mathrm{~V}$ for $20 \mathrm{~s}$. The electrode tip was situated inside the common peroneal nerve, and evoked pain was projected to the ankle joint. During the first stimulus train, delivered at $10 \mathrm{~Hz}$, the subject was instructed to bring the response lever to within the top third of the visual analogue scale when pain was maximal. The magnitude of pain during subsequent stimulus trains at 5, 3 and $1 \mathrm{~Hz}$ was rated relative to the maximum felt at $10 \mathrm{~Hz}$. Note that at $10 \mathrm{~Hz}$ pain magnitude peaks rapidly and plateaus within $3 \mathrm{~s}$ (dashed line) and begins to decay at $14 \mathrm{~s}$. 
ping in the skin in two experiments and by mild muscle twitching in four. However, added sensations were so weak they did not interfere with the subject's rating of pain.

\section{TIME COURSE OF PAIN RATING DURING A STIMULUS TRAIN}

In three preliminary experiments, trains of stimuli were given at $1,2,3,5$ and $10 \mathrm{~Hz}$ for up to $20 \mathrm{~s}$ while the subject continuously monitored the magnitude of pain. At $1 \mathrm{~Hz}$ and $2 \mathrm{~Hz}$ pain onset was rarely signalled before $3-5 \mathrm{~s}$. At $3 \mathrm{~Hz}$ and $5 \mathrm{~Hz}$ pain was felt earlier but had a slow rise time. At $10 \mathrm{~Hz}$ the magnitude of pain peaked within $2 \mathrm{~s}$ and did not decay for at least $10 \mathrm{~s}$. This applied to pain projected to skin as well as to deep structures. Figure 1 shows the steep rise and eventual drop-off of pain rating at
$10 \mathrm{~Hz}$ as opposed to the delayed and slow rise at lower stimulus frequencies.

The decay of pain ratings during prolonged stimulation at $10 \mathrm{~Hz}$ was due to excitation failure of $\mathrm{C}$ fibres. This was shown by monitoring with a proximal electrode the impulse traffic evoked by intraneural stimulation through a distal electrode in the same fascicle of the superfical peroneal nerve at ankle level (fig 2, left). Superimposed neural responses to painful stimulation at $5 \mathrm{~V}$ and at a low stimulus frequency of $0.3 \mathrm{~Hz}$ are displayed in fig $2 \mathrm{~A}$. Discharges in A fibres with conduction velocities down to $7 \mathrm{~m} / \mathrm{s}$ are seen, as well as discharges in C fibres conducting at $2 \cdot 4-1.2 \mathrm{~m} / \mathrm{s}$ (these values may be artificially high in view of the short conduction distance of $45 \mathrm{~mm}$ and the high stimulus intensity). The $C$ fibre reponse is bimodal, with peaks at $2 \mathrm{~m} / \mathrm{s}$ and
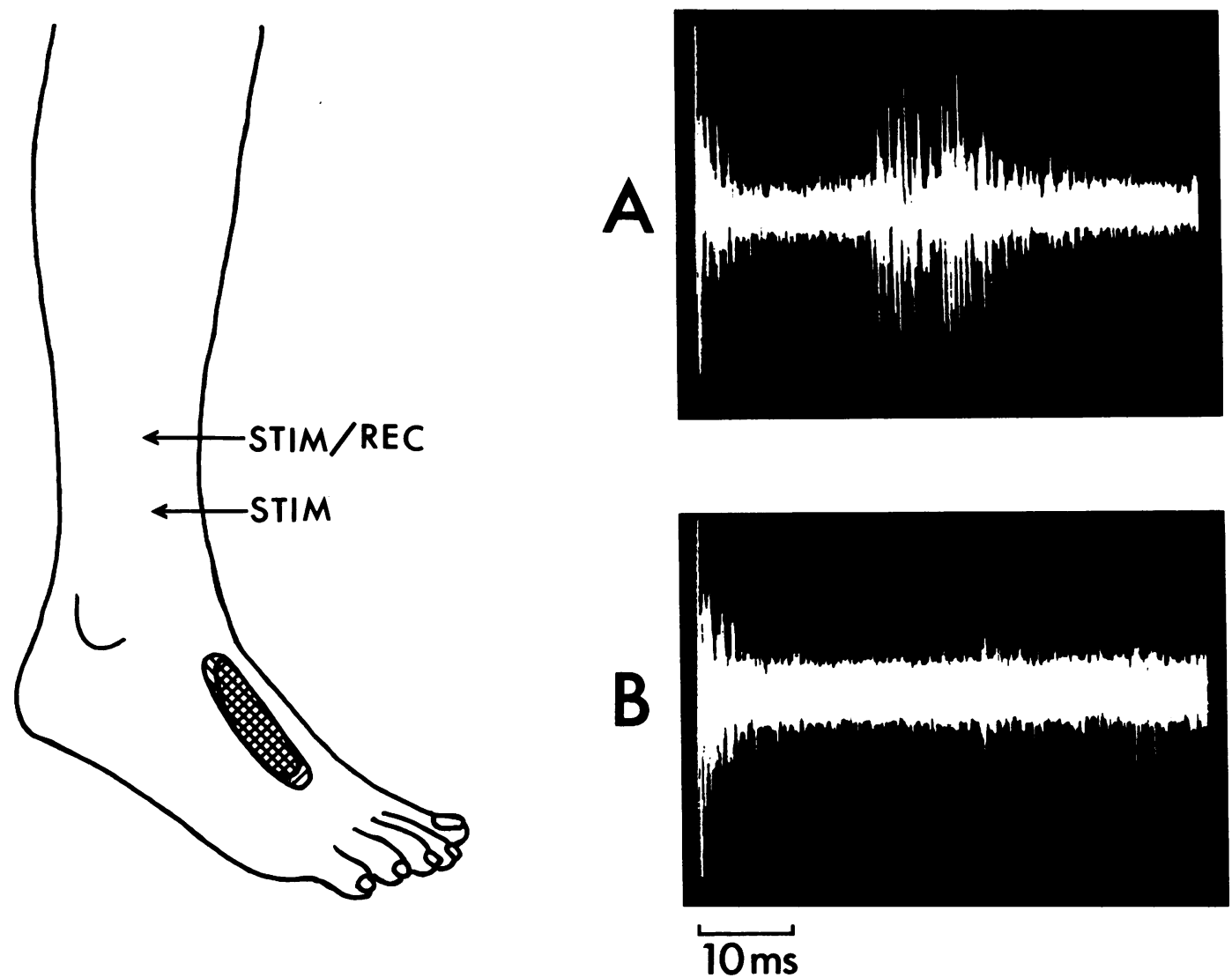

Fig $2 C$ fibre excitation failure at moderately high stimulus frequencies. Two microelectrodes, $4 \cdot 5 \mathrm{~cm}$ apart, have been inserted into the same fascicle of the superficial peroneal nerve, as indicated by the fact that paraesthesiae induced by electrical stimulation through the proximal electrode have the same projection (longitudinally hatched area) as those induced by stimulation through the distal electrode (transversely hatched area). The proximal electrode was then used to record the response evoked by stimulation through the distal electrode. A normal $C$ fibre volley at $5 \mathrm{~V}$ and $0.3 \mathrm{~Hz}$ is shown in $\mathrm{A}$. At $10 \mathrm{~Hz}$ the $C$ potentials increased in latency and disappeared by $30 \mathrm{~s}(\mathrm{~B})$. 
$1.6 \mathrm{~m} / \mathrm{s}$. No increase in latency and no blockings of neural responses were observed at this low stimulus frequency, and the subjective magnitude of pain remained constant. When the stimulation frequency was increased to $10 \mathrm{~Hz}$, the $\mathrm{C}$ fibre response gradually increased in latency until it disappeared entirely at $30 \mathrm{~s}$ (fig 2B). Similarly, we observed a marked latency shift, jitter and eventual blocking of single A delta fibre potentials at $30 \mathrm{~Hz}$ but not at $3 \mathrm{~Hz}$. The decay of the $\mathrm{C}$ and $\mathrm{A}$ delta fibre responses at the higher stimulus frequencies was paralleled by a reduction in the magnitude of evoked pain.

It was thus established that short duration, moderately high frequency stimulus trains are required to obtain a steep rise and rapid peaking of the estimated magnitude of pain, while avoiding depression of nociceptive fibre excitability. We therefore used $3 \mathrm{~s}$ trains at $10 \mathrm{~Hz}$ in all experiments to study the variability in pain ratings over prolonged periods of time.

\section{FLUCTUATIONS IN RATING DURING REPEATED STIMULUS TRAINS OF FIXED DURATION, FREQUENCY AND AMPLITUDE}

In 10 experiments, sequential pain ratings were studied for periods of up to two and a half hours (mean $101 \mathrm{~min}$ ). The duration of an experiment was determined by the length of time it was possible to maintain a stable recording. Stimulus trains were delivered every 5 or $10 \mathrm{~min}$. In one experiment, 10 min intervals were used during the first $100 \mathrm{~min}$ and 5 min intervals thereafter. Evoked pain was projected to the skin in three instances and to muscle, bone or joint in seven.

Sequential pain ratings remained relatively stable as long as there was no electrode shift. There was, however, a tendency for ratings to rise in the first

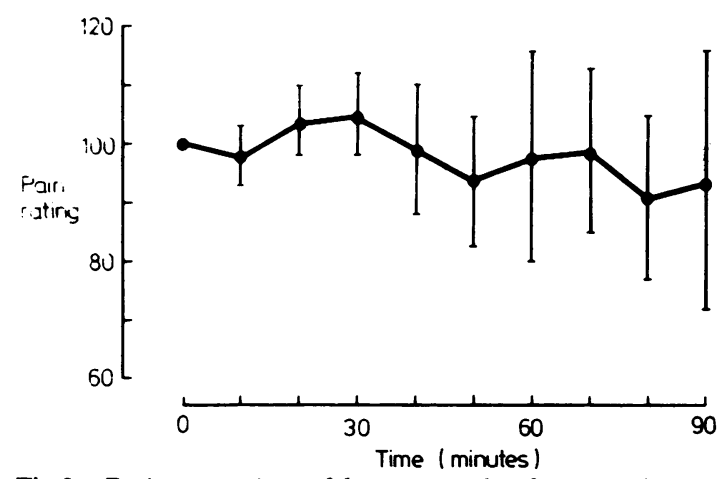

Fig 3 Rating over time of the magnitude of pain evoked by repeated intraneurally delivered stimulus trains. Each dot represents the mean pain rating relative to the standard 100 , bracketed by the $95 \%$ confidence limits. Number of experiments: 10 up to $60 \mathrm{~min}, 9$ at 70 and $80 \mathrm{~min}$, and 6 at 90 min. half hour and then to drop from the standard 100 to around 90 by one and a half hours (fig 3 ). This drop was statistically significant when comparing mean rating at $30 \mathrm{~min}$ with that at $80 \mathrm{~min}(\mathrm{p}<0.05)$ but for no other two values. The gradual decline in ratings continued beyond 90 min to reach a value of 75 at $150 \mathrm{~min}$ in the one experiment where a stable recording could be maintained for this length of time. The initial rise in ratings was obvious only when evoked pain was "contaminated" by mild twitching or cutaneous tactile sensations (fig 4A), and when $10 \mathrm{~min}$ intervals between stimulus trains were used (fig 4B). The subsequent decline in ratings appeared more pronounced with 5 min than with 10 min intervals between trains. Although this difference, like the one between the mean rating curves of "pure" vs. "contaminated" pain, was not statistically significant, the fall-off of ratings with 5 min intervals was sufficiently steep and consistent to suggest that, given larger numbers, it might have become so. In this context, the results of one experiment where both types of intervals were used are of interest. Stimulus trains repeated every 10 min evoked pain whose magnitude was rated at $85-100 \%$ of the standard for $100 \mathrm{~min}$. At this point, the intervals between trains were shortened to 5 min, with the result that pain ratings dropped to
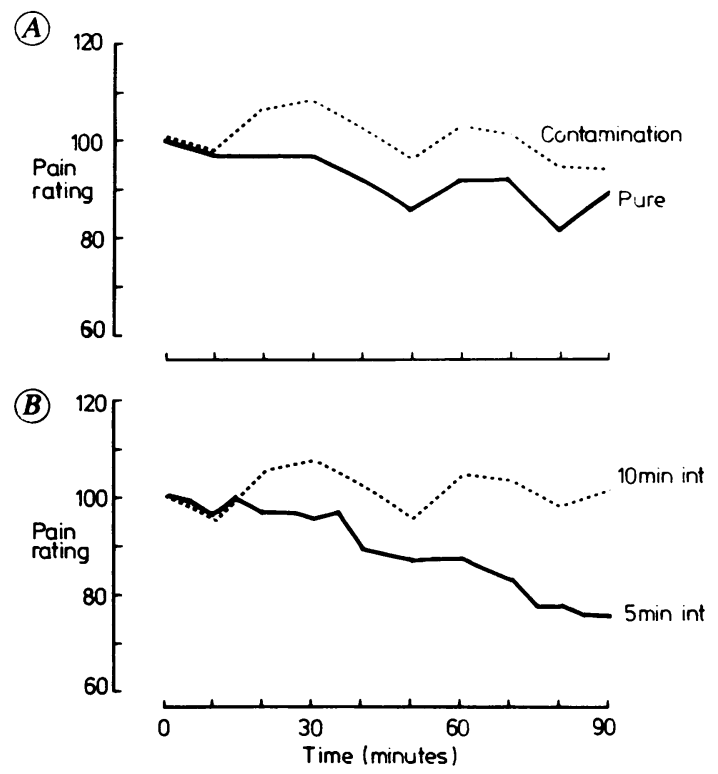

Fig 4 (A) Mean rating curves of experiments where "pure" pain was evoked (continuous line, $n=4$ ) and of experiments where pain was "contaminated" by other sensations (interrupted line, $n=6$ ). (B) Mean rating curves of experiments using 5 min intervals (continuous line, $n=4$ ) and 10 min intervals (interrupted line, $n=7$ ). 
$40 \%$ of the standard $60 \mathrm{~min}$ later despite an unchanged stimulation and recording site.

\section{EFFECT OF ZOMEPIRAC}

In one experiment the effect on pain ratings of a single oral dose of zomepirac $100 \mathrm{mg}$ was studied for $150 \mathrm{~min}$. Intraneural stimulation evoked pain pro- jected to an area overlying the hypothenar eminence. On recording, a $\mathrm{C}$ polymodal nociceptive unit was clearly discriminable, responding to painful electrical, mechanical or heat stimuli applied to the centre of the area of projection of pain (fig 5). Repeated intraneural stimulation elicited a stable rating of the estimated magnitude of pain for $\mathbf{3 0 ~} \mathrm{min}$
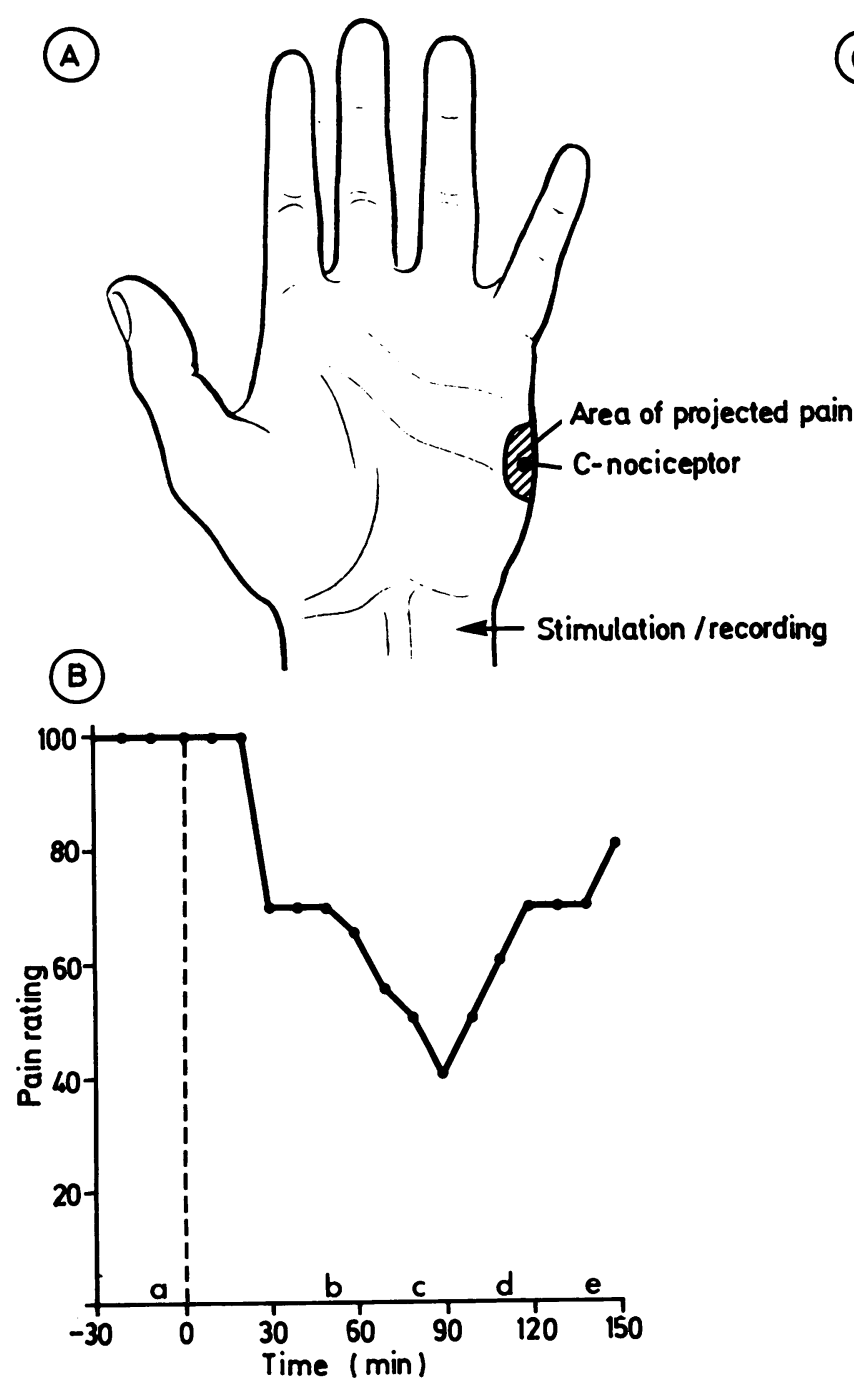

(c)

a

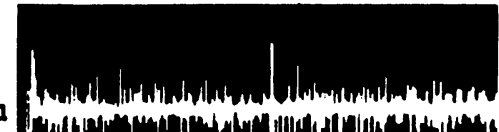

b
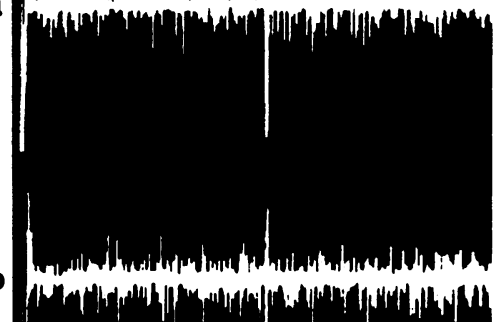

d
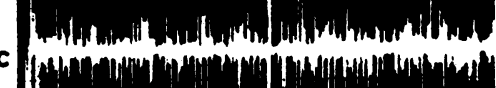

C
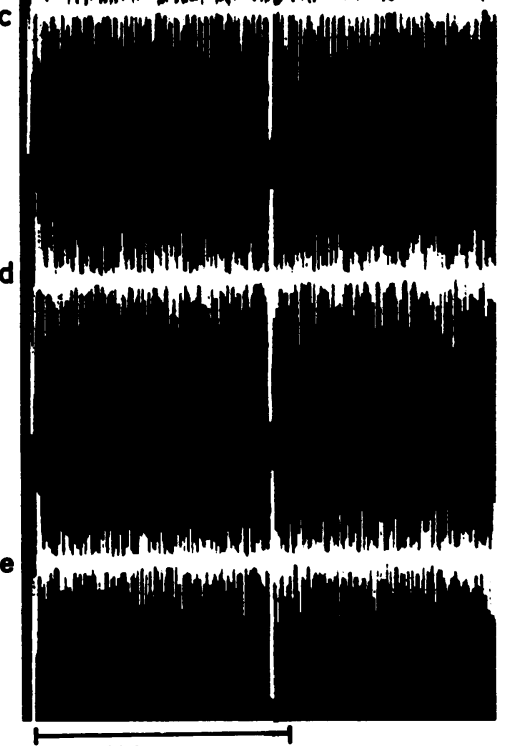

$100 \mathrm{~ms}$

Fig 5 Effect of zomepirac on pain rating. (A) The electrode tip lies in the ulnar nerve at the wrist, and a single $C$ nociceptive unit is discriminable. On intraneural stimulation, pain is projected to an area overlying the unit's receptive field. (B) The estimated magnitude of pain evoked by identical stimulus trains remained stable until 20 min after ingestion of zomepirac $100 \mathrm{mg}$ (0 on the abscissa), then fell gradually to trough at 90 min postingestion, and eventually rose again. (C) C fibre potential evoked by electrical stimulation of the receptive field at 10 min before and $50,80,110$ and 140 min after zomepirac $(a, b, c, d$ and $e$, respectively). Its amplitude and latency did not change, indicating a stable electrode position. 
before and $20 \mathrm{~min}$ after the administration of zomepirac. Ratings then decreased progressively to reach a minimum of $40 \%$ of the standard at around 90 min. Towards the end of the experiment pain ratings increased again. Throughout the experiment, the amplitude and latency of the recordable $\mathrm{C}$ unti potential remained unchanged.

\section{Discussion}

The method described involves excitation of nociceptive units-A delta or $C$ nociceptive fibres, or group IIVIV muscle afferents-directly in the nerves of human subjects without activation of peripheral receptors. That this is possible has been shown in previous reports: nociceptive units can be both selectively recorded from ${ }^{6-8}$ and selectively activated intraneurally. ${ }^{2910}$ In the present work it is likely that unmyelinated fibres were predominantly activated, rather than $A$ delta nociceptive units, which, when projected to skin, mediate very focal pricking or stinging pain. ${ }^{2911}$ By contrast, our subjects usually reported dull pain projected to an area over $1 \mathrm{~cm}$ across, consistent with activation of unmyelinated C fibres. " It is furthermore likely that several unmyelinated axons were activated at the stimulus amplitudes used. A single or a few repeated impulses in a single afferent $\mathrm{C}$ unit are not perceived.9.12 Spatial and temporal summation are required to reach threshold for conscious detection, and much more so in order to reach the suprathreshold pain levels used in our experiments. Figure 1 provides clear evidence of the effect of temporal summation. At a constant stimulation intensity, the time required to reach a certain magnitude of pain is dependent on the stimulus frequency, that is, the number of impulses.

The reason why suprathreshold levels of stimulation were used, when threshold stimulus intensities would have induced pain uncontaminated by either muscle twitching or tactile cutaneous sensations is that, at threshold, evoked pain would have been too weak to allow accurate rating of small increments in magnitude over time. At least moderate pain was required for subjects to detect changes with confidence, both in our study and in previous clinical trials of analgesic drugs. ${ }^{13}$ In any case, while prominent contaminating sensations would be expected to distract the subject and possibly interfere with pain rating by activating some central pain-suppressing "gate", fig 4A shows that mild accompanying muscle twitching or tactile sensations do not appear to affect ratings significantly. Nevertheless, though not indispensable, "pure" uncontaminated pain seems an intrinsically desirable standard in a method to be used for testing pain relief. It is for this reason that later experiments were mostly performed on the common peroneal nerve, which contains proportionately fewer mechanoreceptive units than nerves supplying the glabrous skin of the hand. ${ }^{14} \mathrm{~A}$ higher density of nociceptive units implies a greater chance of evoking "pure" pain during intraneural stimulation.

Pain thresholds differ for various body parts. ${ }^{15}$ In our study, no systematic differences were found between the stimulus intensities required to evoke moderate pain in the upper and in the lower limb. This suggests that observed pain threshold differences are due to variable skin thickness or variable peripheral nociceptor density or sensitivity, but not to central factors. In any case, such variability would have had no effect on our results, since we were concerned with changes in perceived pain relative to an arbitrary standard and not with alteration in absolute thresholds. Two different psychophysical scaling methods were employed to cater for different experimental requirements. A visual analogue scale was used in experiments where pain magnitude was to be rated continuously for short periods, that is, during preliminary experiments designed to establish appropriate stimulus parameters. The advantage of visual analogue scales is their sensitivity and ease of use. ${ }^{16}$ However, in the bulk of our experiments we used a numerical magnitude estimation scale because, with intervals of 5 or $10 \mathrm{~min}$ between stimulus trains, it should be easier to recall previous responses in numerical terms than graphically on a visual analogue scale. This of course introduces number bias into the interpretation of our results ${ }^{17}$-all subjects preferred multiples of 5 -but since there appear to be only about 20 just noticeable differences between pain threshold and the limit of tolerance, ${ }^{15}$ intervals of five points between ratings are the smallest our subjects could have been expected to use, considering their standard for moderate to severe pain was 100 .

The choice of stimulus parameters was set by the need to compromise between the ideal situation of uninterrupted stimulation and pain rating, and the risk of triggering inhibitory mechanisms induced by the electrical stimulation itself. $3 \mathrm{~s}$ trains at $10 \mathrm{~Hz}$ were thought most appropriate for eliciting reproducible experimental pain. Shorter trains or lower frequencies would not have allowed sufficient summation of impulses, while higher frequencies or longer train duration would have led to nociceptive fibre excitation failure, as clearly demonstrated by the result of the double electrode experiment (fig 2). Equally, stimulus trains were not given more frequently than every $5 \mathrm{~min}$ to avoid (a) depression of C fibre excitability and (b) possible central pain- 
suppressing effects. Repeated mechanical activation of $\mathrm{C}$ nociceptors causes a reduction in the $\mathrm{C}$ fibre response, unless intervals between stimuli are over 1 min. ${ }^{18}$ With sustained $10 \mathrm{~Hz}$ stimulation such as we used, the period of $\mathrm{C}$ fibre depression might be expected to be even longer. Moreover, central inhibitory mechanisms may be activated by frequently repeated nociceptive inputs. The painrelieving effect of such "counterirritation" has been demonstrated both clinically and experimentally..$^{15} 1920$ No significant differences in pain ratings over an equivalent time were observed in our study when stimulating at $5 \mathrm{~min}$ and at $10 \mathrm{~min}$ intervals, but there was a trend for ratings to drop with time when using 5 min intervals suggesting pain suppression at central levels. For this reason we would recommend the use of $10 \mathrm{~min}$ intervals in future studies on central activity of analgesic agents.

Two conditions must be satisfied for the method to be used meaningfully: (a) the electrode must be placed in such a position that intraneural stimulation causes exclusively or predominantly pain, and (b) the electrode tip must remain in a stable position in the nerve, as judged by unchanging recordable activity, so that the number of nociceptive fibres excited by identical electrical shocks does not alter. The first requirement is not absolute, since the technique has been employed to study the pain-relieving effects of vibration and cooling when coactivating nociceptors and mechanoreceptors. ${ }^{21}$ However, activation of non-nociceptive units in large numbers introduces unknown factors which may affect the reproducibility of the method. Under carefully controlled conditions, the method may thus be a reliable, if technically difficult, way of studying the central effects of pain-relieving procedures and, in particular, of analgesic drugs. The result of the pilot study with zomepirac indicates that the method is applicable in practice. The drop in and subsequent recovery of pain ratings following a single dose of the drug, in the setting of an extremely stable electrode position, suggest that zomepirac does have central analgesic effects in addition to inhibiting prostaglandin synthesis in the periphery. This has already been postulated on the basis of neurophysiological and immunological tests in experimental animals. ${ }^{22} 23$ However, confirmation of this finding in man awaits a controlled study using a method such as the one described.

We gratefully acknowledge support from the Swedish Medical Research Council (Grants No. 5206-06, 6153-02 and 5822-02), the National Institutes of Health (Grant No. 1R01NS18315-01) and McNeil Pharmaceuticals.

\section{References}

' Vallbo $\AA$ B, Hagbarth K-E. Activity from skin mechanoreceptors recorded percutaneously in awake human subjects. Exp Neurol 1968;21:270-89.

2 Torebjörk HE, Ochoa JL. Specific sensations evoked by activity in single identified sensory units in man. Acta Physiol Scand 1980;110:445-7.

${ }^{3}$ Vallbo ÅB, Hagbarth K-E, Torebjörk HE, Wallin BG. Somatosensory, proprioceptive and sympathetic activity in human peripheral nerves. Physiol Rev 1979;59:919-57.

${ }^{4}$ Ochoa JL, Torebjörk HE. Sensations evoked by intraneural microstimulation of single mechanoreceptor units innervating the human hand. J Physiol (Lond) 1983;342:633-54.

${ }^{5}$ Schady WJL, Torebjörk HE. Projected and receptive fields: a comparison of projected areas of sensations evoked by intraneural stimulation of mechanoreceptive units, and their innervation territories. Acta Physiol Scand 1983;119:267-75.

- Torebjörk HE. Afferent $\mathrm{C}$ units responding to mechanical, thermal and chemical stimuli in human nonglabrous skin. Acta Physiol Scand 1974;92:374-90.

7 Torebjörk HE, Hallin RG. C-fibre units recorded from human sensory nerve fascicles in situ. Acta Soc Med Uppsal 1970; 75:81-84.

${ }^{8}$ Hees J van, Gybles JM. Pain related to single afferent C fibres from human skin. Brain Res 1972;48:397-400.

9 Torebjórk HE. Human microneurography and the problems of pain. Jap $J$ Electroenc Electromyogr 1981 ;Suppl 169-175.

${ }^{10}$ Torebjörk HE, Ochoa JL. Selective stimulation of sensory units in man. In: Bonica JJ, Lindblom U, Iggo A, eds. Advances in Pain Research and Therapy, Vol 5. New York: Raven 1983:99-104.

" Schady WJL, Torebjörk HE, Ochoa JL. Peripheral projections of nerve fibres in the human median nerve. Brain Res 1983;277:249-261.

12 Torebjörk HE, Hallin RG. Identification of afferent C units in intact human skin nerves. Brain Res 1974;67:387-403.

${ }^{13}$ Lasagna L. Analgesic methodology: a brief history and commentary. J Clin Pharmacol 1980;20:373-6.

${ }^{14}$ Sunderland S, Lavarack JO, Ray LJ. The caliber of nerve fibres in human cutaneous nerves. J Comp Neurol 1949;91:87-101.

is Hardy JD, Wolff HG, Goodell, H. Pain Sensations and Reactions. Hafner: New York, 1952:86-172.

${ }^{16}$ Scott J, Huskisson EC. Graphic representations of pain. Pain 1976;2:175-84.

17 Baird JC, Lewis C, Romer D. Relative frequencies of numerical responses in ration estimation. Percept Psychophys 1970;8:358-62.

${ }^{18}$ Perl ER. Myelinated afferent fibres innervating the primate skin and their response to noxious stimuli. J Physiol 1968;197:593-615.

${ }^{19}$ Melzack R. Prolonged relief of pain by brief, intense transcutaneous somatic stimulation. Pain 1975;1:357-73.

${ }^{20}$ LeBars D, Dickenson AH, Besson J-M. Diffuse noxious inhibitory controls (DNIC). I. Effects of dorsal horn 
convergent neurones in the rat. Pain 1979;6:283-304.

${ }^{21}$ Bini G, Cruccu G, Hagbarth K-E, Schady W, Torebjörk HE. Analgesic effect of vibration and cooling on pain induced by intraneural electrical stimulation. Pain. 1984;18:239-48.

22 Divinetz-Romero S, Yaksh TL, Muschek LD, O'Neill PJ. In vivo studies on the effect of zomepirac sodium on cat CSF levels of prostaglandin E2 (PGE2). Soc Neurosci Abstr 1981;7:882.

${ }^{23}$ Yezierski RP, Wilcox TK, Willis WD. Effects of zomepirac sodium on primate spinothalamic tract cells. In: Bonica JJ, Lindblom U, Iggo A, eds. Advances in Pain research and Therapy, Vol. 5. New York: Raven 1983:635-41. 